\title{
Sensory Perceptions of Virgin Olive Oil: New Panel Evaluation Method and the Chemical Compounds Responsible
}

\author{
Diana De Santis, Maria Teresa Frangipane \\ Department for Innovation in Biological, Agro-Food and Forest Systems (DIBAF), Tuscia University, Viterbo, \\ Italy \\ Email: mtfrangi@unitus.it
}

Received 20 February 2015; accepted 10 March 2015; published 13 March 2015

Copyright (C) 2015 by authors and Scientific Research Publishing Inc.

This work is licensed under the Creative Commons Attribution International License (CC BY). http://creativecommons.org/licenses/by/4.0/

cC) (i) Open Access

\begin{abstract}
The stimulation of the human sensory receptors by compounds present in virgin olive oils (VOOs) gives rise to the sensory attributes that describe its particular aroma. The sensor panel evaluation and the molecules responsible for sensory perceptions of virgin olive oil quality are elucidated. The methodology for the evaluation of the sensory characteristics of VOOs is reported, and typical flavours and off-flavours are described. Relationships between chemical compounds and sensory characteristics are evaluated using the new sensory analyses method promoted by the International Olive Oil Council (IOOC) and included recently in EU regulation (Reg. 1348/2013 and following revisions). Oil quality may be defined in a number of ways, but the sensory perception of flavour is the ultimate determinant.
\end{abstract}

\section{Keywords}

Olive Oil, Volatile Compounds, Sensory Attributes, Off-Flavours

\section{Introduction}

Virgin olive oils (VOOs) are defined by the European Community as those “...oils obtained from the fruit of the olive tree solely by mechanical or other physical means under conditions that do not lead to alteration in the oil...” (EEC Reg. 2568/91).

VOOs represent the main source of fats in the countries of the Mediterranean basin where the production of olive oil is concentrated. Recent studies [1]-[3] have evidenced the beneficial effects on health of the so-called "Mediterranean diet". Numerous research studies have proved that some non-volatile compounds are related in 
an indirect way to positive effects on human health [4]-[6], whereas sensory attributes are directly ascribable to the strong stimulation of human sensory receptors by volatile and some non-volatile compounds [7]-[9] present in virgin olive oil. Phenolic compounds stimulate the tasting receptors and also the free endings of the trigeminal nerve eliciting the former with the bitterness perception and the latter with pungency and astringency [10] [11]. Volatile compounds are low-molecular weight compounds (less than $300 \mathrm{Da}$ ) that vaporise readily at room temperature, which by stimulating the olfactive receptors, are responsible for the whole aroma of the virgin olive oil [10] [12]-[16]. The major volatile compounds reported in VOOs are the C6 and the C5 volatile compounds. C6 and C5 compounds are enzymatically produced from polyunsaturated fatty acids through the so-called lipoxygenase (LOX) pathway and their concentrations depend on the level; the activity of each enzyme involved in this LOX pathway is reported in Figure 1 [15]-[18].

The best way to comprehend aroma development is the understanding of the various enzyme pathways, which provide the formation of olive oil volatile compounds. In general, the release of enzymes at the cell destruction stage can be considered the switch-on of the lipoxygenase pathway. In the first step of volatile formation, acyl hydrolase $(\mathrm{AH})$ hydrolyses triglycerides and phospholipids release free fatty acids. The second step is defined by the formation of hydroperoxides for the lipoxygenase (LOX) that oxidise the fatty acids released by the action of AH. The enzyme is more active with linolenic acid than with linoleic acid by a factor of two. The highest LOX activity for linolenic acid supports the biogenesis of more of the six-carbon unsaturated volatile compounds, which are the major constituents of the virgin olive oil aroma. Olive fruits show highest LOX activity 15 weeks after anthesis, this activity decreasing during the development and ripening period [18]. Hydroperoxide lyase (HPL) catalyzes the cleavage of fatty acid hydroperoxides, producing volatile aldehydes and oxoacids. The HPL enzyme can yield C6 aldehydes and C12 $\omega$-oxoacids from the 13-hydroperoxides of linolenic or linoleic acid, or C9 aldehydes from the 9-hydroperoxide derivates of the same fatty acids, depending on the substrate specificity of the enzyme. The highest level of HPL activity is detected in green olive fruits harvested at initial developmental stages. Alcohol dehydrogenase (ADH) catalyzes the reversible reduction of aliphatic aldehydes to alcohols that contribute to the aroma of vegetable products. There is a decline in ADH activity when the olive fruit changes to a purple colour during the ripening process and thus the content of C6 alcohols decreases. Alcohols, produced

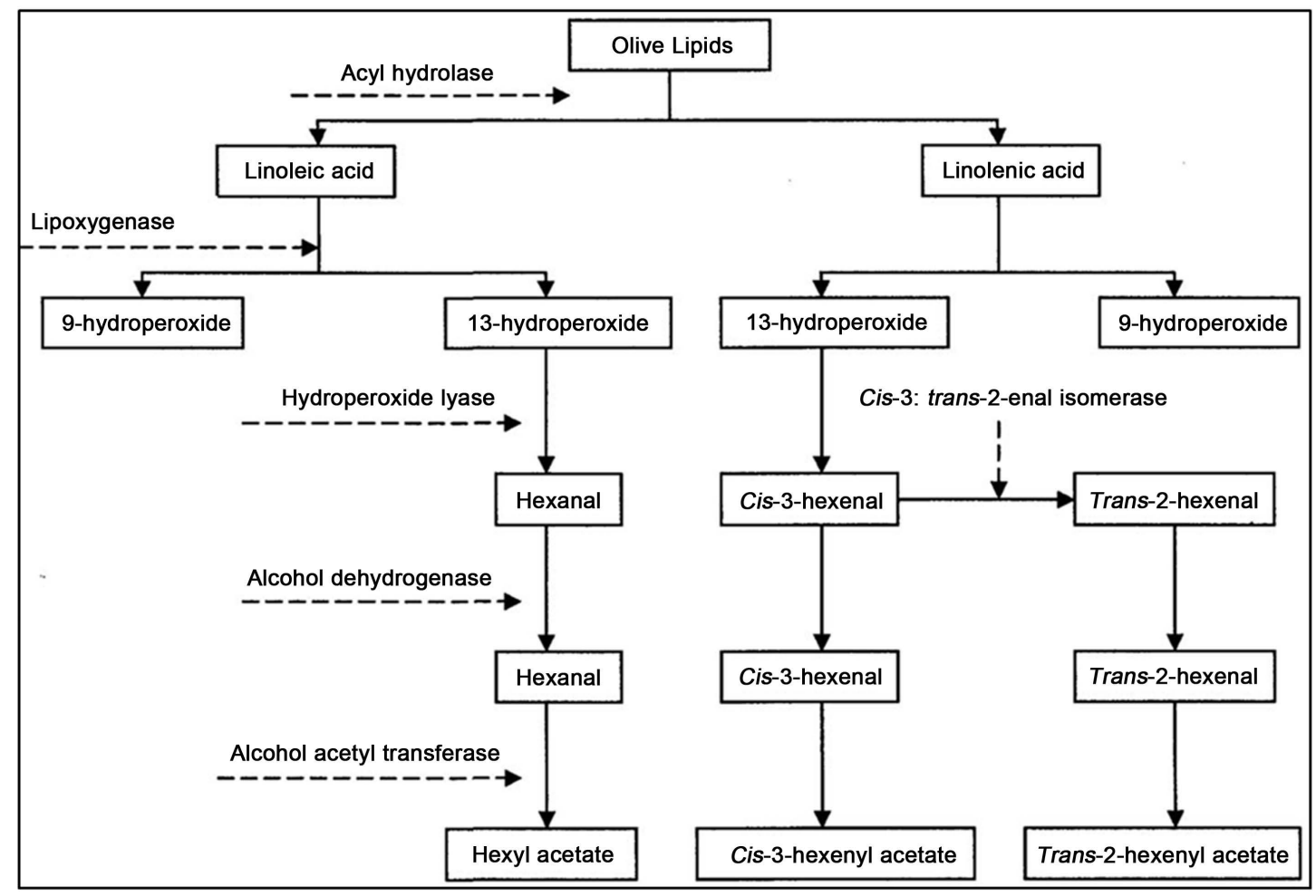

Figure 1. Pathway for the formation of major volatile compounds in virgin olive oils (adapted from Ridolfi et al. 2002). 
by the action of $\mathrm{ADH}$, can form volatile esters. Alcohol acetyltransferase (AAT) catalyzes the formation of acetate esters through acetyl-CoA derivates. In olive oils, ethyl propionate and hexyl acetate are significant components of the sweet, fruity note.

It should be emphasized that the high-concentration volatile compounds are not necessarily the major contributors of odour [18]. Cultivar, geographic region, fruit maturity, processing methods and parameters influence the volatile composition of olive oil [16]-[21]. The large increase in demand for high-quality olive oil is thought to be related to its peculiar organoleptic characteristics that play an important role in human nutrition [12].

Conversely, all compounds, strongly affecting sensory receptors, can decisively influence food acceptability, direct the preference of consumers and, in short, to a great extent, determine the quality of life.

\section{Sensory Evaluation of Virgin Olive Oil: COI-Panel Test}

Sensory analysis is still the most effective tool to evaluate quality, but a common perplexity regarding the sensory evaluation of virgin olive oil is represented by the fact that each tester judges the organoleptic characteristics subjectively. For this reason, collaborative international studies, supported by the International Olive Oil Council (IOOC), developed a quantitative descriptive analysis (QDA) sensory methodology for virgin olive oil, known as the COI-Panel test. This methodology defines a specific vocabulary of sensory attributes (Table 1) and outlines a uniform testing technique, thereby eliminating any problems that may compromise the sensory trial [1]. The purpose of this international method is to determine the criteria required to assess the characteristics of the flavour of virgin olive oil, and is applicable in its classification, according to the intensity of the defects as determined by a group of testers selected and trained as a panel. This group, ranging from 8 - 12 members, is designated in a codified manner and suitably trained to identify and measure the strength of the negative and positive attributes. A defined structured scale is used for measuring the intensity of the different attributes. Since tasters are considered as measurement instrument, it is absolutely essential to remove or, at least, to minimize any possible problems that could compromise the sensory trial. The shape and dimension of the glass, sample volume, and oil temperature are precisely established (COI/T20/Doc.15/Rev.6/2013). Samples, never numerous in order to avoid sense organ fatigue, are presented in an anonymous and random way. A profile sheet is utilized (Figure 2) which considers the negative attributes (e.g., fusty, musty, muddy sediment, winey-vinegary, metallic and rancid) being those most commonly detectable in virgin olive oil [22]-[27]. Other defects described in the specific vocabulary (Table 1) can be named by means of designation to "others". Furthermore the profile sheet presents only fruity, bitter and pungent among positive notes. The tester indicates, on the profile sheet provided, the intensity with which each of the negative and positive attributes are perceived using an unstructured scale. A $100 \mathrm{~mm}$ long unstructured scale, was chosen to overcome the problems deriving from the fact that the amplitude of all intervals of the old structured scale could not be considered equally by tasters and to the reluctance of tasters to use the extreme portions of the structured scales.

The median value of the defect perceived with the strongest intensity identifies the olive oil grade; the median value of the fruity attribute identifies the olive oil category (Table 2). When the median of the bitter and/or pungent attribute is more than 5.0 this will be indicated by the panel supervisor on the oil test certificate. Evaluation of the sensory quality of virgin olive oils involves perception of both favourable and unfavourable sensory attributes, with evaluation of sensory defects being used to classify oils into various grades [14].

When analyses are carried out either to check for compliance with the standard or for a second opinion, the panel supervisor will have the organoleptic assessment performed in triplicate, with at least one day elapsing between each test. The median of attributes will be calculated from the set of profile sheet data for the three tests. Statistical procedures were applied to evaluate the data provided by assessors and produced results that, due to their significance levels, could be considered as reliable as those of other methods usually adopted in scientific fields. The reliability of panel assessors is measured by the robust coefficient of variation that should be $\leq 20 \%$ for the median of defects in extra virgin and virgin categories and $\leq 10 \%$ in lampante. For the fruity median it should be $\leq 10 \%$ in extra virgin and virgin categories. The method has been included in EU regulation (Reg. n.1989/03 and following revisions). The maintenance of the panel is carried out by continuous training over the duration of the life of the same panel, checking of the sensory acuity of tasters, and by methods that permit the measurement of panel performance. Every year, all panels must assess a number of reference samples in order to verify the reliability of the results obtained and to harmonize the perception criteria; they must also update the Member State on their activity and on any composition changes within their group. Actually, the 
Table 1. Specific vocabulary for virgin olive oil (COI/T20/Doc.15/Rev.6/2013 e Reg. EU 1348/13).

\begin{tabular}{|c|c|c|}
\hline \multicolumn{3}{|l|}{ Negative attributes: } \\
\hline$\underline{\text { Fusty/muddy sediment }}$ & \multicolumn{2}{|c|}{$\begin{array}{l}\text { Characteristic flavour of oil obtained from olives piled or stored in such conditions as to have } \\
\text { undergone an advanced stage of anaerobic fermentation, or of oil which has been left } \\
\text { in contact with the sediment that settles in underground tanks and vats and which } \\
\text { has also undergone a process of anaerobic fermentation. }\end{array}$} \\
\hline Musty-humid-earthy & \multicolumn{2}{|c|}{$\begin{array}{l}\text { Characteristic flavour of oils obtained from fruit in which large numbers of fungi and yeasts } \\
\text { have developed as a result of its being stored in humid conditions for several days or of oil obtained } \\
\text { from olives that have been collected with earth or mud on them and which have not been washed. }\end{array}$} \\
\hline$\frac{\text { Winey-vinegary }}{\underline{\text { acid-sour }}}$ & \multicolumn{2}{|c|}{$\begin{array}{l}\text { Characteristic flavour of certain oils reminiscent of wine or vinegar. This flavour is mainly due to } \\
\text { a process of aerobic fermentation in the olives or inolive paste left on pressing mats which have } \\
\text { not been properly cleaned and leads to the formation of acetic acid, ethyl acetate and ethanol. }\end{array}$} \\
\hline$\underline{\text { Rancid }}$ & \multicolumn{2}{|c|}{ Flavour of oils which have undergone an intense process of oxidation. } \\
\hline$\frac{\text { Frostbitten olives }}{\text { (wet wood) }}$ & \multicolumn{2}{|c|}{ Characteristic flavour of oils extracted from olives which have been injured by frost while on the tree. } \\
\hline \multicolumn{3}{|l|}{ Other negative attributes: } \\
\hline Heated or burnt & \multicolumn{2}{|c|}{$\begin{array}{l}\text { Characteristic flavour of oils caused by excessive and/or prolonged heating during processing, } \\
\text { particularly when the paste is thermally mixed, if this is done under unsuitable thermal conditions. }\end{array}$} \\
\hline Hay-hood & \multicolumn{2}{|c|}{ Characteristic flavour of certain oils produced from olives that have dried out. } \\
\hline$\underline{\text { Rough }}$ & \multicolumn{2}{|c|}{ Thick, pasty mouth feel sensation produced by certain oils. } \\
\hline Greasy & \multicolumn{2}{|c|}{ Flavour of oil reminiscent of that of diesel oil, grease or mineral oil. } \\
\hline$\underline{\text { Vegetable water }}$ & \multicolumn{2}{|c|}{ Flavour acquired by the oil as a result of prolonged contact with vegetable water. } \\
\hline$\underline{\text { Brine }}$ & \multicolumn{2}{|c|}{ Flavour of oil extracted from olives which have been preserved in brine. } \\
\hline$\underline{\text { Metallic }}$ & \multicolumn{2}{|c|}{$\begin{array}{l}\text { Flavour that is reminiscent of metals. It is characteristic of oil which has been } \\
\text { in prolonged contact with metallic surfaces during crushing, mixing, pressing or storage. }\end{array}$} \\
\hline$\underline{\text { Esparto }}$ & \multicolumn{2}{|c|}{$\begin{array}{l}\text { Characteristic flavour of oil obtained from olives pressed in new esparto mats. } \\
\text { The flavour may differ depending on whether the mats are made of green esparto or dried esparto. }\end{array}$} \\
\hline$\underline{\text { Grubby }}$ & \multicolumn{2}{|c|}{$\begin{array}{c}\text { Flavour of oil obtained from olives which have been heavily attacked } \\
\text { by the grubs of the olive fly (Bactrocera oleae). }\end{array}$} \\
\hline$\underline{\text { Cucumber }}$ & \multicolumn{2}{|c|}{$\begin{array}{l}\text { Flavour produced when an oil is hermetically packed for too long, particularly } \\
\text { in tin containers and which is attributed to the formation of } 2-6 \text { nonadienal. }\end{array}$} \\
\hline \multicolumn{3}{|l|}{ Positive attributes: } \\
\hline$\underline{\text { Fruity }}$ & \multicolumn{2}{|c|}{$\begin{array}{l}\text { Set of olfactory sensations characteristic of the oil which depends on the variety and comes from } \\
\text { sound, fresh olives, either ripe or unripe. It is perceived directly and/or through the back of the nose. }\end{array}$} \\
\hline$\underline{\text { Bitter }}$ & \multicolumn{2}{|c|}{$\begin{array}{l}\text { Characteristic primary taste of oil obtained from green olives or olives turning colour. } \\
\text { It is perceived in the circumvallate papillae on the "V" region of the tongue. }\end{array}$} \\
\hline Pungent & \multicolumn{2}{|c|}{$\begin{array}{l}\text { Biting tactile sensation characteristic of oils produced at the start of the crop year, primarily from olives } \\
\text { that are still unripe. It can be perceived throughout the whole of the mouth cavity, particularly in the throat. }\end{array}$} \\
\hline Median of defects & Median of fruity aroma & Olive oil category \\
\hline 0 & $>0$ & Extra virgin \\
\hline$>0 \leq 3.5$ & $>0$ & Virgin \\
\hline$>3.5$ & $>0$ & Lampante \\
\hline$\leq 3.5$ & 0 & Lampante \\
\hline
\end{tabular}


COI/T.20/Doc. No15/Rev. 6

page 11

Figure 2

PROFILE SHEET FOR VIRGIN OLIVE OIL

INTENSITY OF PERCEPTION OF DEFECTS

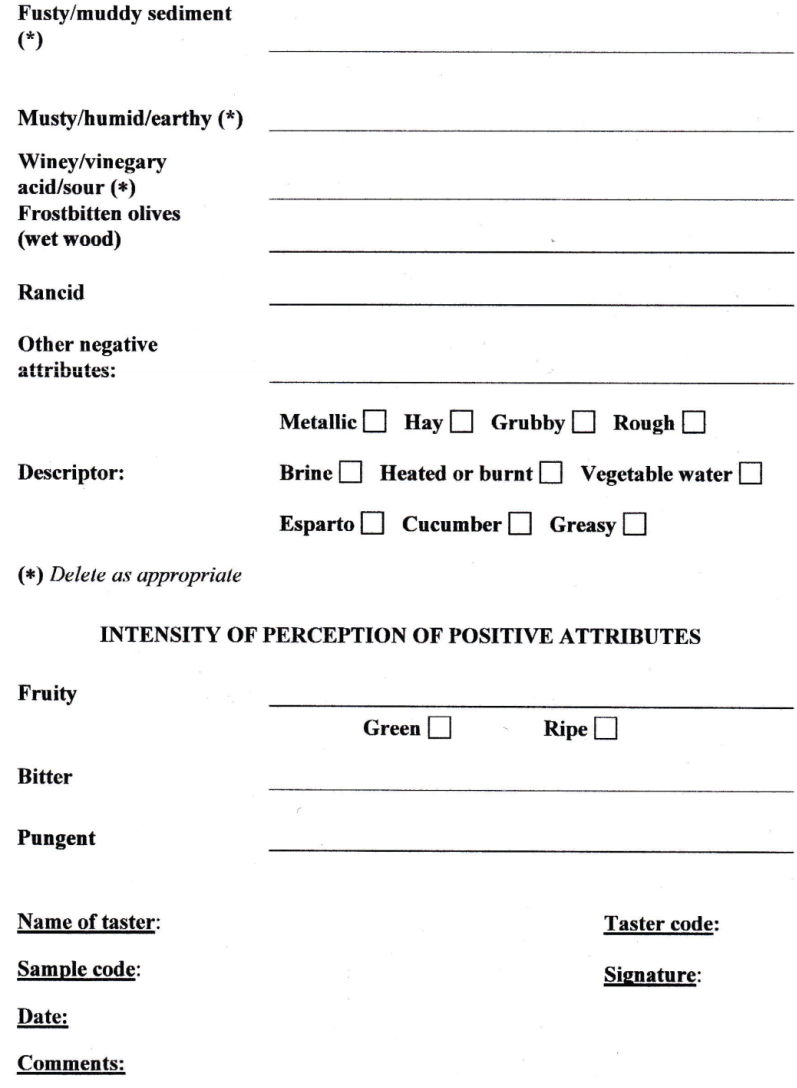

Figure 2. Profile sheet actual adopted by EU regulation.

most important result for sensory analysis of VOO is the identification of the presence of defects rather than the evaluation of positive attributes, in compliance with the aim of such an analysis, which is essentially to classify the product in different commercial classes.

Upon request, the panel leader may certify that the oils, which have been assessed, comply with the definitions and ranges corresponding to the following adjectives according to the intensity and perception of the attributes:

Positive attributes (fruity, bitter and pungent): According to the intensity of perception:

Intense-when the median of the attribute is more than 6 ;

Medium — when the median of the attribute is between 3 and 6;

Light - when the median of the attribute is less than 3.

Fruity: set of olfactory sensations characteristic of the oil which depends on the variety of olive and comes from sound, fresh olives in which neither green nor ripe fruitiness predominates. It is perceived directly and/or through the back of the nose.

Greenly fruity: set of olfactory sensations characteristic of the oil which is reminiscent of green fruit, depends on the variety of olive and comes from green, sound, fresh olives. It is perceived directly and/or through the back of the nose.

Ripely fruity: set of olfactory sensations characteristic of the oil which is reminiscent of ripe fruit, depends on the variety of olive and comes from sound, fresh olives. It is perceived directly and/or through the back of the nose. 
Well balanced: oil which does not display a lack of balance, by which is meant the olfactory-gustatory and tactile sensation where the median of the bitter and/or pungent attributes is two points higher than the median of the fruitiness.

Mild oil: oil for which the median of the bitter and pungent attributes is 2 or less [27].

In 2005, the IOOC issued a document on methods to be used for the organoleptic assessment of EVOO for granting designation of origin (D.O.) status (IOOC/T.20/Doc. no 22). In the case of specifications for the designation of origin of some D.O. oils, it is first necessary to verify that the sample has the characteristics provided in the extra virgin category using current methods (UE Reg. 1348/13), and to subsequently analyze it to verify the presence of characteristic descriptors. The final score for the D.O must be at least 7, but can be even higher.

\section{Relationships between Chemical Compounds and the Sensory Characteristics of Virgin Olive Oils}

The concentrations of the different volatile compounds may be related to some sensory notes. In some cases this presupposition proved true: as an example, the amount of trans-2-heptenal was found to be related to the degree of oil rancidity or the concentrations of ethanol and ethyl acetate which are related to the winey defect. But the simple concentrations of volatile compounds cannot take into account the complex interactions occurring in the olfactory system either between taste and smell, or between oral trigeminal irritations and taste and smell [28] [14]. Indeed, the relationships do not always result from the interactions between a single odor note and a single volatile compound, but sometimes from the connections between a single attribute and the sum of the volatile compounds [29]. On the other hand, the volatile compounds of the virgin olive oil do not contribute to its whole aroma with the same importance. What is more, the influence of different volatile compounds must be evaluated not only on the basis of their concentration, but also on the basis of their sensory thresholds, whose determination is also affected by individual differences in sensitivity observed in human normal subjects [30] [31].

The essential role played by hexanal in the formation of most of the green attributes is confirmed by several researchers [32] [33] who studied possible correlations between fruity, leaf, almond, banana, freshly cut grass, walnut husk, wild flowers, tomato, bitter, pungent, and sweet attributes, and the concentrations of compounds deriving from the LOX pathway. In order to evaluate the bitter taste in extra virgin olive oils (EVOOs), some authors [34] have proposed a simple analytical method based on the extraction of the bitter compounds measured by spectrophotometric determination at $225 \mathrm{~nm}$, reporting a good correlation with the bitter taste evaluated by sensory analysis. Moreover, other authors [35] have proposed an easy method to estimate the oil bitterness intensity by measuring the total phenol content. However, in both cases, a predictive model has not been validated with unknown oil samples. Besides, an experimental investigation was performed on blended EVOOs from different cultivars with the aim of evaluating the possibility of estimating the perceived bitterness intensity by using chemical indices, such as the total phenol content and the compounds responsible for oil bitterness measured spectrophotometrically at $225 \mathrm{~nm}$ (K225 value), as bitterness predictors in different EVOO. The results indicated that the oil bitterness intensity could be satisfactorily predicted by using the K225 values of oil samples [36]. It is of interest that, due to the positive contribution of the phenolic compounds to the oxidative stability of the olive oil and to human health, consumers are increasing their consumption of oils with high bitterness intensity [37]. Although it is clearly known that polyphenols are the main contributors to olive oil bitterness and astringency, the contribution of each individual polyphenol to the total bitterness is not yet clear; a strong correlation between the concentration of secoridoidderivates of hydroxytyrosol and bitterness has been found, but only if one olive variety is used or in oils in which these compounds are the main components [38].

Using a trained olive oil sensory panel, some investigators [39] have studied the temporal perception of bitterness and pungency with a time-intensity (TI) evaluation technique. It was shown that the bitterness curves had a faster rate of increase and decline than the pungency curves. It was also demonstrated that differences in kinetic perception are linked to the slower signal transmission of thermal nociceptors compared to other neurons.

In general, it is correct to surmise that from healthy olives, picked at the right degree of ripening and properly processed, it is always possible to obtain an extra virgin olive oil; otherwise, from unhealthy or fallen olives it is inevitable that an olive oil characterized by unpleasant flavours and sensory defects will be produced. Long malaxing times are associated with a significant increase in the total volatile compounds, a decrease in volatile compounds responsible for the pleasant aroma of virgin olive oil and elevated production of 2-methyl butanol and 3-methyl butanol associated with sensory defects [40]. 


\section{Origin of Off-Flavours}

When oils are of poor quality the sensory basic characteristics are considerably modified. Green, bitter and pungent notes are absent or very weakly perceived by tasters who identify the presence of some unpleasant sensations in the flavour.

\subsection{Defects from Bad Sanitary Conditions of Fruits}

An essential aspect to obtain high quality oils is the sanitary conditions of fruits. Grubby, is the most common defect typical of oils obtained from olives which have suffered a Bactrocera oleae infestation. Changes in the phenolic compounds and also in the volatile composition of oils are very considerable [41].

\subsection{Defects from Wrong Harvesting Procedure}

Olive harvesting is an important operation that contributes to a good quality of oil. Ground picked olives are the defect of oils obtained from fallen olives which have remained on the ground for several days. In fact, the contact between the olives and the ground causes an increase in the content of volatile alcohols and carbonyl compounds with the appearance of a typical defect, which can be described by mouldy [42] [43].

\subsection{Defects from Unsuitable Conditions of Olive Fruit Preservation}

Time and fruit storage conditions play an essential role in determining the appearance of off-odours such as fusty (typical of oils obtained from olives stored in piles which suffered degradative phenomena), winey (typical of oils obtained from olives stored in piles which suffered some fermentation) and musty (typical of oils obtained from olives stored in piles which suffered the more or less considerable fungal invasion). The profile of aromatic compounds is significantly modified during the olive preservation period. Indeed, the amount of the all volatile compounds, expressed as ppm of nonan-1-ol, decreases by about $30 \%-40 \%$ in oils obtained from olives preserved for $15 \mathrm{~d}$ in relation to that detected in oils from fresh fruits [40].

\subsection{Defects from Unsuitable Extraction Technology}

When the olives are processed without washing, the resulting oils are characterised by a defective aroma reminiscent of wet earth; in fact this defect is typical of oils obtained from fruits collected together with earth. Another defect related to technological aspects is a metallic attribute, typical of oils extracted both at new processing plants and in plants used for the first time during the crop year; moreover under these conditions free fatty acids contained in the oils dissolve the thin layer of iron oxide that covers the plant surfaces during the period in which the plant is not used, imparting the metallic defect to the oil [31]. Concerning the malaxation phase, which consists of a slow kneading of the olive paste, the time-temperature pair should be carefully controlled to obtain a high quality EVOO. The lipoxygenase pathway is triggered by the milling of olives and is active during malaxation. The volatile compounds produced are incorporated into the oil phase to confer its characteristic aroma. Specifically, a temperature above $28^{\circ} \mathrm{C}$ for more than $45 \mathrm{~min}$ should be avoided; in fact, these conditions can lead to the deactivation of enzymes that produce both positive volatile compounds and oxidize the phenolic compounds causing changes in oil flavor. The too long times or too high temperatures adopted during the malaxation step can induce the appearance of the heated defect. This defect is related to the production of high amounts of 2-methyl butanal and 3-methyl butanal [44].

\subsection{Defects from Unsuitable Oil Storage Conditions}

Rancid is the most common defect related to the unsuitable oil preservation, typical of oils strongly oxidized. Oxidation is an inevitable process that starts after the virgin olive oil has been extracted and leads to deterioration that becomes serious during incorrect oil storage. During oil preservation the original volatile composition changes, the concentration of $\mathrm{C}_{6}$ aldehydes, especially that of trans-2-hexenal, and $\mathrm{C}_{6}$ alcohols decreases, while the amount of $C_{5}-C_{11}$ aldehydes increases; these aldehydes contribute mainly to undesirable aromas [45].

Another type of sensory defect can appear during oil preservation: muddy sediment, typical of oils stored for a long time on their sediment. In fact, after a few months a layer of sediment is formed at the bottom of the container in which oil is stored; this sediment can ferment and give rise to the production of unpleasant com- 
pounds.In unfiltered oil, the low quantities of sugars or proteins that remain for extended times in oil can be fermented or degraded by specific anaerobic micro-organisms of the Clostridium genus, producing volatile compounds responsible for an unpleasant muddy odour by butyric fermentation. Filtration of newly-produced oil can avoid this phenomenon [46].

\section{Consumer Acceptability of the Sensory Characteristics of V0O}

The quality of virgin olive oil is not always correctly perceived by the consumer. Generally, consumers appreciate what is familiar, what is strongly linked to the territory (tradition/origin) [47] [48]. For a correct perception of the overall quality the fruity (green or ripe) and bitter and pungent attributes should be perceived by consumers as "healthy" indicators of quality [49]. However, consumers do not appear to practice an informed consumption of EVOO.

A study in Italy [47] demonstrated that information about origin creates a favourable hedonic expectation, regarding specific sensory attributes, such as pungency and bitterness. To confirm this opportunity to perceive pungent as a positive attribute a paper can be cited [50]. The authors hypothesize that this pungency, distinguishing particularly good olive oils within the European Union standard, similar to other common food irritants turns, from a usually negative taste-kinesthetic sensation into positive, because the molecules that elicit it have a body healthy action. In the case of EVOO it's important that consumers are actually able to appreciate its fundamentals of sensory profile (fruity, bitter, pungent) as related to its quality [51].

\section{Conclusions}

At present, even taking recent development of sensory analysis into account, there is no other food that has such a highly controlled environment regulated by the EU, the International Olive Oil Council and, as with any food product, Codex Alimentarius (FAO-OMS). Therefore, the challenge for the future is to improve the education of consumers in the appreciation of fundamental attributes of quality.

Nowadays, the key to providing the consumer with a truly effective knowledge of EVOO quality could be in the dissemination of all sensory attributes related to "healthy" and in the ability to recognize the presence of defects.

The quality of oil may be defined in a number of ways, but the sensory perception of flavour is the ultimate determinant.

\section{References}

[1] Keys, A. (1995) Mediterranean Diet and Public Health: Personal Reflections. American Journal of Clinical Nutrition, 61, 1321S-1323S.

[2] Lipworth, L., Martinez, M.E., Angell, J., Hsieh, C.C. and Trichopoulos, D. (1997) Olive Oil and Human Cancer: An Assessment of the Evidence. Preventive Medicine, 26, 181-190. http://dx.doi.org/10.1006/pmed.1996.9977

[3] Psaltopoulou, T., Kosti, R., Haidopoulos, D., Dimopoulos, M., and Panagiotakos, D. (2011) Olive Oil Intake Is Inversely Related to Cancer Prevalence: A Systematic Review and a Meta-Analysis of 13800 Patients and 23340 Controls in 19 Observational Studies. Lipids in Health and Disease, 10, 127-132. http://dx.doi.org/10.1186/1476-511X-10-127

[4] Visioli, F., Bellomo, G., Montedoro, G.F. and Galli, C. (1995) Low Density Lipoprotein Oxidation Is Inhibited in Vitro by Olive Oil Constituents. Atherosclerosis, 117, 25-32. http://dx.doi.org/10.1016/0021-9150(95)05546-9

[5] Fabiani, R., Rosignoli, P., De Bartolomeo, A., Fuccelli, R., Servili, M., Montedoro, G.F. and Morozzi, G. (2008) Oxidative DNA Damage Is Prevented by Extracts of Olive Oil, Hydroxytyrosol, and Other Olive Phenolic Compounds in Human Blood Mononuclear Cells and HL60 Cells. The Journal of Nutrition August, 138, 1411-1416.

[6] Manna, C., Galletti, P., Cucciolla, V., Montedoro, G.F. and Zappia, V. (1999) Olive Oil Hydroxytyrosol Protects Human Erythrocytes against Oxidative Damages. The Journal of Nutritional Biochemistry, 10, 159-165. http://dx.doi.org/10.1016/S0955-2863(98)00085-0

[7] Angerosa, F., Di Giacinto, L. and D’Alessandro, N. (1997) Quantitation of Some Flavor Components Responsible for the "Green" Attributes in Virgin Olive Oils. Journal of High Resolution Chromatography, 20, 507-510. http://dx.doi.org/10.1002/jhrc.1240200909

[8] Aparicio, R., Morales, M.T. and Alonso, M.V. (1996) Relationship between Volatile Compounds and Sensory Attributes of Olive Oils by the Sensory Wheel. Journal of American Oil Chemistry Society, 73, 1253-1264. 
http://dx.doi.org/10.1007/BF02525454

[9] Angerosa, F. and Di Giovacchino, L. (1996) Natural Antioxidants of Virgin Olive Oil Obtained by Two and Tri-Phase Centrifugal Decanters. Grasas Aceites, 47, 247-254. http://dx.doi.org/10.3989/gya.1996.v47.i4.866

[10] Morales, M.T. and Tsimidou, M. (2000) The Role of Volatile Compounds and Polyphenols in Olive Oil Sensory Quality. In: Harwood, R.J., Ed., Handbook of Olive Oil. Analysis and Properties, Aspen Publishers, Gaithersburg, 393-458. http://dx.doi.org/10.1007/978-1-4757-5371-4_12

[11] Angerosa, F., Servili, M., Selvaggini, R., Taticchi, A., Esposto, S. and Montedoro, G.F. (2004) Volatile Compounds in Virgin Olive Oil: Occurrence and Their Relationship with the Quality. Journal of Chromatography A, 1054, 17-31. http://dx.doi.org/10.1016/j.chroma.2004.07.093

[12] Angerosa, F. (2002) Influence of Volatile Compounds on Virgin Olive Oil Quality Evaluated by Analytical Approaches and Sensor Panels. European Journal of Lipid Science and Technology, 104, 639-660. http://dx.doi.org/10.1002/1438-9312(200210)104:9/10<639::AID-EJLT639>3.0.CO;2-U

[13] Angerosa, F. (1994) Olive Oil Flavour and Aroma: Biochemistry and Chemistry of Sensory Factors Affecting Consumer Appreciation and Their Analysis by Artificial Intelligence. AIR European Project AIR3-CT94, The Commission of the European Communities.

[14] Angerosa, F. (2000) Sensory Quality of Olive Oils. In: Harwood, J. and Aparicio, R. Eds., Handbook of Olive Oil, Analysis and Properties, Aspen Publications, Inc., Gaithersburg, 355-392. http://dx.doi.org/10.1007/978-1-4757-5371-4_11

[15] Angerosa, F. and Basti, C. (2001) Olive Oil Volatile Compounds from the Lipoxygenase Pathway in Relation to Fruit Ripeness. Italian Journal of Food Science, 13, 421-428.

[16] Angerosa, F., Basti, C. and Vito, R. (1999) Virgin Olive Oil Volatile Compounds from Lipoxygenase Pathway and Characterization of Some Italian Cultivars. Journal of Agricultural and Food Chemistry, 47, 836-839. http://dx.doi.org/10.1021/jf980911g

[17] Reiners, J. and Grosch, W. (1998) Odorants of Virgin Olive Oils with Different Flavor Profiles. Journal of Agricultural and Food Chemistry, 46, 2754-2763. http://dx.doi.org/10.1021/jf970940b

[18] Ridolfi, M., Terenziani, S., Patumi, M. and Fontanazza, G. (2002) Characterization of the Lipoxygenases in some Olive Cultivars and Determination of Their Role in Volatile Compounds Formation. Journal of Agricultural and Food Chemistry, 50, 835-839. http://dx.doi.org/10.1021/jf0109118

[19] Inarejos-Garcia, A.M., Gómez-Rico, A., Salvador, M.D. and Fregapane, G. (2010) Effect of Preprocessing Olive Storage Conditions on Virgin Olive Oil Quality and Composition. Journal of Agriculture and Food Chemistry, 58, 48584865. http://dx.doi.org/10.1021/jf902486f

[20] Inarejos-Garcia, A.M., Santacatterina, M., Salvador, M.D., Fregapane, G. and Gómez-Alonso, S. (2010) PDO Virgin Olive Oil Quality-Minor Components and Organoleptic Evaluation. Food Research International, 43, 2138-2146. http://dx.doi.org/10.1016/j.foodres.2010.07.027

[21] Tanouti, K., Serghini-Caid, H., Sindic, M., Wathelet, J.P., Bouseta, A. and Elamrani, A. (2012) Volatile Compounds, Profiles of Virgin Olive Oils Produced in the Eastern Morocco: Oxidative Stability and Sensory Defects. Journal of Food Research, 1, 194-206.

[22] Commission Regulation (EEC) No. 2568/91 of 11 July 1991 on the Characteristics of Olive Oil and Olive Residue Oil and on the Relevant Methods of Analysis. Official Journal, L248, 1-83.

[23] UE Regulation No. 1348/2013 of 16 December 2013 on Change of EC Regulation No. 2568/91.

[24] IOOC (1987) International Olive Oil Council, Doc. T.20/n.3, Madrid June 18th.

[25] IOOC (1996) International Olive Oil Council, Doc. T.20/n.15/Rev.1, Madrid November 20th.

[26] IOOC (2013) International Olive Oil Council, Doc. T.20/n.14/Rev.4, Madrid May 4th.

[27] IOOC (2013) International Olive Oil Council, Doc. T.20/n.15/Rev.6, Madrid November 2013.

[28] Erickson, R.P. and Covey, E. (1980) On the Singularity of Taste Sensations: What Is a Taste Primary? Physiology \& Behavior, 25, 527-533. http://dx.doi.org/10.1016/0031-9384(80)90117-1

[29] Piggott, J.R. (1990) Relating Sensory and Chemical Data to Understand Flavor. Journal of Sensory Studies, 4, $261-272$. http://dx.doi.org/10.1111/j.1745-459X.1990.tb00477.x

[30] Angerosa, F., DiGiacinto, L. and Solinas, M. (1992) Influence of Dacusoleae Infestation on Flavor of Oils, Extracted from Attacked Olive Fruits, by HPLC and HRGV Analyses of Volatile Compounds. Grasas y Aceites, 43, $134-142$. http://dx.doi.org/10.3989/gya.1992.v43.i3.1165

[31] Kalua, C.M., Allen, M.S., Bedgood, D.R., Bishop, A.G., Prenzler, P.D. and Robards, K. (2007) Olive Oil Volatile Compounds, Flavour Development and Quality: A Critical Review. Food Chemistry, 100, 273-286. 
http://dx.doi.org/10.1016/j.foodchem.2005.09.059

[32] Angerosa, F., Mostallino, R., Basti, C. and Vito, R. (2000) Virgin Olive Oil Odour Notes: Their Relationships with Volatile Compounds from the Lipoxygenase Pathway and Secoiridoid Compounds. Food Chemistry, 68, 283-287. http://dx.doi.org/10.1016/S0308-8146(99)00189-2

[33] Di Giovacchino, L. (2000) Technological Aspects. In: Harwood, J. and Aparicio, R., Eds., Handbook of Olive Oil. Analyses and Properties, Aspen Publication, Inc., Gaithersburg, 17-59. http://dx.doi.org/10.1007/978-1-4757-5371-4 2

[34] Gutierrez Rosales, F., Perdiguero, S., Gutierrez, R. and Olias, J.M. (1992) Evaluation of the Bitter Taste in Virgin Olive Oil. Journal of the American Oil Chemists Society, 69, 394-395. http://dx.doi.org/10.1007/BF02636076

[35] Beltràn, G., Ruano, M.T., Jimenez, A., Uceda, M. and Aguilera, M.P. (2007) Evaluation of Virgin Olive Oil Bitterness by Total Phenol Content Analysis. European Journal of Lipid Science and Technology, 108, 193-197. http://dx.doi.org/10.1002/ejlt.200600231

[36] Favati, F., Condelli, N., Galgano, F. and Caruso, M.C. (2013) Extra Virgin Olive Oil Bitterness Evaluation by Sensory and Chemical Analyses. Food Chemistry, 139, 949-954. http://dx.doi.org/10.1016/j.foodchem.2013.01.098

[37] Inarejos-Garcia, A.M., Androulaki, A., Salvador, M.D., Fregapane, G. and Tsimidou, M.Z. (2009) Discussion on the Objective Evaluation of Virgin Olive Oil Bitterness. Food Research International, 42, 279-284. http://dx.doi.org/10.1016/j.foodres.2008.11.009

[38] Andrewes, P., Busch, J.L.H., De Joode, T., Groenewegen, A. and Alexandre, H. (2003) Sensory Properties of Virgin Olive Oil Polyphenols: Identification of Deacetoxy-Ligstrosideaglycon as a Key Contributor to Pungency. Journal of Agricultural and Food Chemistry, 51, 1415-1420. http://dx.doi.org/10.1021/jf026042j

[39] Sinesio, F., Moneta, E. and Esti M. (2005) The Dynamic Sensory Evaluation of Bitterness and Pungency in Virgin Olive Oil. Food Quality and Preference, 16, 557-564. http://dx.doi.org/10.1016/j.foodqual.2004.12.002

[40] Angerosa, F., Mostallino, R., Basti, C. and Vito, R. (2001) Influence of Malaxation Temperature and Time on the Quality of Virgin Olive Oils. Food Chemistry, 72, 19-28. http://dx.doi.org/10.1016/S0308-8146(00)00194-1

[41] Gómez-Caravaca, A.M., Cerretani, L., Bendini, A., Segura-Carretero, A., Fernandez-Gutierrez, A., DeCarlo, M., Compagnone, D. and Cichelli, A. (2008) Effects of Fly Attack (Bactrocera oleae) on the Phenolic Profile and Selected Chemical Parameters of Olive Oil. Journal of Agriculture and Food Chemistry, 56, 4577-4583. http://dx.doi.org/10.1021/jf800118t

[42] Angerosa, F., Di Giacinto, L., Basti, C. and De Mattia, G. (1995) Caratterizzazione del difetto di “cascola”. Rivista Italiana Delle Sostanze Grasse, 72, 61-65.

[43] Angerosa, F., Lanza, B. and Marsilio, V. (1996) Biogenesis of Fusty Defect in Virgin Olive Oils. Grasas y Aceites, 47, 142-150. http://dx.doi.org/10.3989/gya.1996.v47.i3.854

[44] Servili, M., Selvaggini, R., Taticchi, A., Esposito, S. and Montedoro, G.F. (2003) Volatile Compounds and Phenolic Composition of Virgin Olive Oil: Optimization of Temperature and Time of Exposure of Olive Pastes to Air Contact during the Mechanical Extraction Process. Journal of Agriculture and Food Chemistry, 51, 7980-7988. http://dx.doi.org/10.1021/jf034804k

[45] Bendini, A., Cerretani, L., Salvador, M.D., Fregapane, G. and Lercker, G. (2009) Stability of the Sensory Quality of Virgin Olive Oil during Storage: An Overview. Italian Journal of Food Science, 21, 389-406.

[46] Lozano-Sanchez, J., Cerretani, L., Bendini, A., Segura-Carretero, A. and Fernandez-Gutierrez, A. (2010) Filtration Process of Extra Virgin Olive Oil: Effect on Minor Components, Oxidative Stability and Sensorial and Physicochemical Characteristics. Trends in Food Science \& Technology, 21, 201-211. http://dx.doi.org/10.1016/j.tifs.2009.12.004

[47] Caporale, G., Policastro, S., Carlucci, A. and Monteleone, E. (2006) Consumer Expectations for Sensory Properties in Virgin Olive Oils. Food Quality and Preference, 17, 116-125. http://dx.doi.org/10.1016/j.foodqual.2005.07.011

[48] Costell, E., Tárrega, A. and Bayarri, S. (2010) Food Acceptance: The Role of Consumer Perception and Attitudes. Chemosensory Perception, 3, 42-50. http://dx.doi.org/10.1007/s12078-009-9057-1

[49] Carluccio, M.A., Siculella, L, Ancora, M.A., Massaro, M., Scoditti, E., Storelli, C., Visioli, F., Distante, A. and De Caterina, R. (2003) Olive Oil and Red Wine Antioxidant Polyphenols Inhibit Endothelial Activation: Antiatherogenic Properties of Mediterranean Diet Phytochemicals. Arteriosclerosis, Thrombosis, and Vascular Biology, 23, 622-629. http://dx.doi.org/10.1161/01.ATV.0000062884.69432.A0

[50] Peyrot Des Gachons, C., Uchida, K., Bryant, B., Shima, A., Sperry, J.B., Dankulich-Nagrudny, L., Tominaga, M., Smith III, A.B., Beauchamp, G.K. and Breslin, P.A.S. (2011) Unusual Pungency from Extra-Virgin Olive Oil Is Attributable to Restricted Spatial Expression of the Receptor of Oleocanthal. Journal of Neuroscience, 31, 999-1009. http://dx.doi.org/10.1523/JNEUROSCI.1374-10.2011 
[51] Cecchi, T., Passamonti, P., Alfei, B. and Cecchi, P. (2011) Monovarietal Extra Virgin Olive Oils from the Marche Region, Italy: Analytical and Sensory Characterization. International Journal of Food Properties, 14, 483-495.

http://dx.doi.org/10.1080/10942910903254811 